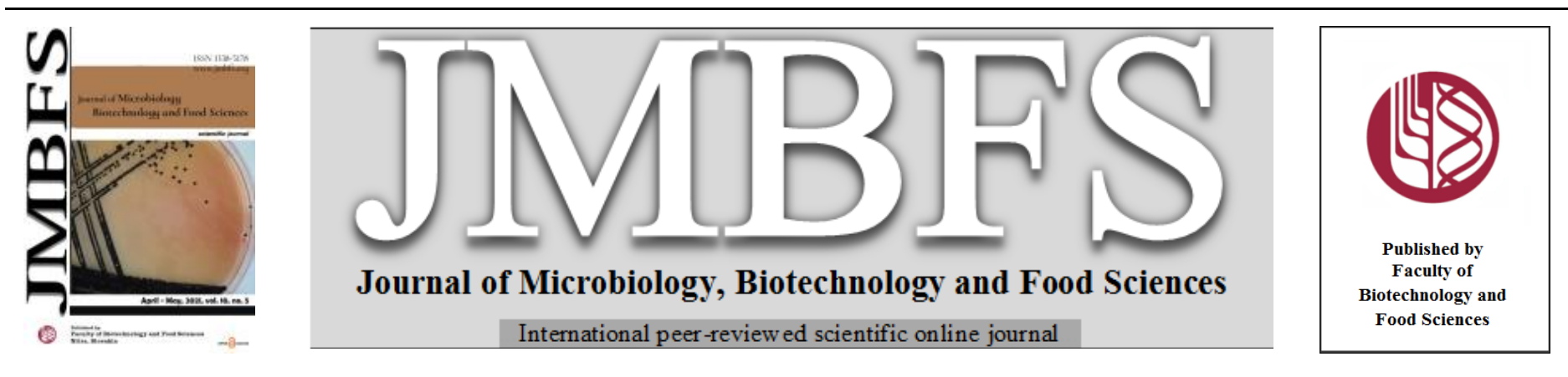

\title{
CYTOLOGICAL STUDY ON RAT ISOLATED HEPATOCYTES AND POSSIBLE PROTECTION OF GINGER (EXTRACT AND NANOPARTICLES) AGAINST ACETAMINOPHEN TOXICITY
}

\author{
Alaa F. Bakr', Sherein S. Abdelgayed ${ }^{1}$ Osama S. EL-Tawil ${ }^{2}$, Adel M. Bakeer $*^{1}$ \\ Address(es): \\ ${ }^{1}$ Department of Pathology, Faculty of Veterinary Medicine, Cairo University, 12211, Giza, Egypt. \\ ${ }^{2}$ Department of Toxicology and Forensic Medicine, Faculty of Veterinary Medicine, Cairo University, 12211, Giza, Egypt.
}

*Corresponding author: sherein.abdelgayed@vet.cu.edu.eg

https://doi.org/10.15414/jmbfs.2681

\section{ARTICLE INFO}

Received 23. 2. 2020

Revised 4. 12. 2020

Accepted 7. 12. 2020

Published 1. 4. 2021

Regular article

OPEN $\partial_{\text {ACCESS }}$

\begin{abstract}
Ginger is one of most important medicinal plants which used in variable diseases. Recently, ginger nanoparticles have been isolated from ginger extract and exhibited anti-apoptotic activity, hepatoprotective effect against alcohol and may effectively reduce colitis. Our study aimed to compare between the effect of ginger extract and ginger nanoparticles at concentration of $60 \mu \mathrm{g} / \mathrm{ml}$ against hepatotoxicity caused by acetaminophen (APAP; N-acetyl-para-aminophenol) at concentration of $0.1 \mathrm{mg} / \mathrm{ml}$ using primary isolated rat hepatocytes. Cytotoxicity was determined by assessing cell viability and leakage of cytosolic enzymes, such as (ALT\& AST). Oxidative stress was investigated by measuring levels of MDA and catalase enzymes. The cytopathological lesions were detected by light microscope. Exposure of isolated rat hepatocytes to APAP caused cytotoxicity and oxidative injury, manifested by loss of cell viability and significant increase of enzymes leakages. Also, APAP caused progressive depletion of catalase content and increase in intracellular MDA accumulation, in addition to alteration in histological structures of the cells. Pretreatment of hepatocytes with either GE or GNPs ameliorated the hepatotoxicity, oxidative stress and enzymatic leakage induced by APAP. However, GNPs were more effective compared to ginger extract pre-treated hepatocytes.
\end{abstract}

Keywords: Acetaminophen, Ginger extract, Ginger nanoparticles, Isolated hepatocytes, Cytology, Rats

\section{INTRODUCTION}

Liver is considered as one of an important organs which responsible for the metabolic process in our bodies (Adam et al., 2016). The continuous using of synthetic drug could induce oxidative stress and tissue injury of multiple organs including liver (Rashid $\boldsymbol{e t}$ al., 2016). One of these drugs is acetaminophen (APAP) which used in treatment of fever and reducing of pain (Kandemir $\boldsymbol{e t}$ al., 2017). At a high dose, APAP could induced liver injury which confirmed by using lab animals and isolated hepatocytes in multiple studies (Woolbright \& Jaeschke, 2017). Acetaminophen caused liver toxicity by production of $\mathrm{N}$ acetyl-p-benzoquinoneimine (NAPQI), which exhibit mitochondrial oxidative stress, apoptosis, necrosis and DNA fragmentation (Ramachandran \& Jaeschke, 2017).

Recently, herbal medicines are got more attention by scientists especially after appearance of antibiotic resistant bacteria and increasing of the side effects of synthetic drugs (Mekuriya \& Mekibib, 2018). One of most popular herbal plant is ginger, which has variable pharmacological activities such as antiinflammatory, cardiovascular activities (Yang et al., 2014), anti-cancer activities (Dhanik et al., 2017), and hepto-protective effects (Hamed et al., 2012 ; Gabr et al., 2019). Also, ginger used to manufacture of artificial nanoparticles such as $\mathrm{Fe} 3 \mathrm{O} 4, \mathrm{ZnO} \mathrm{Ag}$, and $\mathrm{Au}$ in process named by "green synthesis"(Dhayalan et al., 2017 ; Stan et al., 2017).

Ginger has veterinary importance, it can increase the rate of feed up take by improving the appetite of animal (Shams Al-dain and Jarjeis, 2015). Also, ginger has the ability to reduce the recovery time in equine after racing event and hard exercise (Mekuriya \& Mekibib, 2018). On the other hand, ginger can promote the weight gain and performance of poultry (Khan et al., 2012) and being helpful in treatment of Mycoplasma gallisepticum (Sutardi et al., 2015). As well as protecting the fish from microorganisms, including bacteria causing skin lesions such as E. coli and Staphylococcus aureus and fungi (Shakya, 2015).

Ginger (Zingiber officinale Roscoe), an indigenous plant in tropical Asia and probably in southern China and India, has a long life, cane-like plant with annual leafy stalks (Hassan \& Hassan, 2018). The pharmacological properties of ginger are attributed to its active ingredients such as gingerols and shogaols, which exhibit a strong anti-oxidant and anti- apoptotic actions (Dhanik et al., 2017). Shogaols are the dehydrated form of gingerols (Wang $\boldsymbol{e t}$ al., 2017). In spite of, the structure similarity of both shogaols and gingerols (Sirichote et al., 2008), Shogaols exhibit stronger antioxidant than gingerols due to it was absorbed faster and the $t 1 / 2$ was longer than gingerols (Li et al., 2019).

Natural nanoparticles which isolated from edible plant act in a way like mammalian exosomes, they are containing protein, lipids and miRNA. Moreover, natural nanoparticles are easily produced relative to synthetic NPs (Zhang $\boldsymbol{e t}$ al., 2017). In addition, Isolation of natural nanoparticles from plant can provide a safe method to drug delivery within the body without induced side effects such as synthetic nanoparticles (Abdu et al., 2017).

Ginger nanoparticles (GNPs) is one of natural nanoparticles which isolated from ginger extract are characterized by stability in stomach (Zhang $\boldsymbol{e t}$ al., 2017), and easily distributed from the intestine to the liver which consider the targeted organ by GNPs (Zhuang $\boldsymbol{e t}$ al., 2015).Ginger nanoparticles did not induce changes in the body weight, blood parameters and histological structures of different organs (Zhang et al., 2018). On the other hand, GNPs have been reported to exhibit hepatoprotective effect (Zhuang et al., 2015; Bakr et al., 2019), and treatment of intestinal disease (Zhang et al., 2017), and colitis (Zhang et al., 2018).

Thus, in our in vitro study we assessed the hepatoprotective properties of isolating ginger nanoparticles relative to ginger extract using acetaminophen as a hepatotoxic compound and compare the results with our previous in vivo study (Bakr et al., 2019), to examine the possibility of using GNPs in drug delivery without causing any side effects.

\section{MATERIAL AND METHODS}

\section{Animals}

This study was performed by using five Sprague Dawley adult male rats (120 $150 \mathrm{~g}$ ) were obtained from VACSERA Company (Egypt). All methods used in this protocol were accepted by the Institutional Animal Care and Use Committee (IACUC) as defined in the Cairo University guidelines (Approval ID: CUIIS5617). The animals were housed in polyethylene plastic cages at ambient temperature of $\left(25 \pm 2{ }^{\circ} \mathrm{C}\right)$, humidity $(40-50 \%)$, and a light- dark cycle of 12 
hours. Rats were adapted for 7 days before start of the study supplied with pelleted balanced diet and tap water ad libitum.

\section{Chemicals}

Acetaminophen was purchased as prepared finished powder from Sigma Chemical Co. (Saint Louis, USA).

\section{Preparation of ginger extract}

Fresh ginger roots were purchased from local market. The dried roots of ginger were compressed into powder by using blender. $125 \mathrm{~g}$ of the powder were macerated in $1 \mathrm{~L}$ of distilled water for $12 \mathrm{hr}$ at room temperature and were then filtered through a $5 \mu \mathrm{m}$ filter to get the final extract. The concentration of the extract is $24 \mathrm{mg} / \mathrm{ml}$ (Sakr et al., 2011). We used this stoke to prepare GE at concentration equal to $60 \mu \mathrm{g} / \mathrm{ml}$ based on the previous in vitro study (PashaeiAsl et al., 2017).

\section{Preparation of ginger nanoparticles}

Quantity of washed roots equal to $200 \mathrm{gm}$ were powdered by using a mixer at the highest speed for $10 \mathrm{~min}$. After that, ginger juice was then centrifuged in sequence as following (1,000 g for $10 \mathrm{~min} / 3,000 \mathrm{~g}$ for $20 \mathrm{~min} / 10,000 \mathrm{~g}$ for 40 $\mathrm{min}$ ), then pellet was resuspended in $3 \mathrm{ml}$ of PBS and referred to as microparticles. The supernatant was then spin at 150,000g for $90 \mathrm{~min}$ by using ultra speed centrifuge followed by resuspension of the pellet in $3 \mathrm{ml}$ PBS. After that a freeze- drying process was made to remove water from nanoparticles after it is frozen and placed under vacuum to keep NPs stable for long time, this process named by (lyophilization). We used this stoke to prepare NPs at concentration of equal to $60 \mu \mathrm{g} / \mathrm{ml}$ (Zhuang et al., 2015).

\section{Characterization of nanoparticles: Morphology and Size}

Lyophilized (unhydrated) ginger nanoparticles morphology, diameter, and size distribution were determined using scanning electron microscopy (SEM) (XL-30 ESEM- FEG SEM, FEI Company, USA). Average diameters of 500 particles were determined from SEM images $(n=3)$ using image analysis software (ImageJ, National Institutes of Health, version 1.5a, ImageJ.nih.gov) (Mahmoud et al., 2019).

\section{Isolation of hepatocytes}

The hepatocytes were isolated from rat by a collagenase two-step perfusion technique as described by Abdel-Aleem et al. (2014). Rat was anaesthetized by using ketamine $(100 \mathrm{mg} / \mathrm{kg}$ ip). The abdominal cavity was incised to reveal the liver which perfused in situ with calcium-free Hank's bicarbonate buffer for 8 $\mathrm{min} / 37^{\circ} \mathrm{C}$ through portal vein using a polyethylene cannula. Perfused liver was dislocated from the abdominal cavity and recirculated in collagenase $(0.67 \mathrm{mg} / \mathrm{ml})$ containing $5 \mathrm{mM}$ calcium chloride for $10 \mathrm{~min}$. The freshly isolated hepatocytes were filtrated through cotton gauze and centrifuged for $2 \mathrm{~min}$ at $600 \mathrm{rpm}$. Isolated hepatocytes were washed twice by low-speed centrifugation followed by resuspension in HEPES-bicarbonate buffer containing $0.5 \%$ bovine albumin $(\mathrm{pH}$ 7.4). After that the cells were suspended Trypan Blue in Krebs Hanseliet buffer to assess the viability albumin $(\sim 85-90 \%)$.

\section{Experimental Protocol}

In this study, the concentration of acetaminophen (APAP) was adjusted to $7 \mathrm{mM}$ $(0.1 \mathrm{mg} / \mathrm{ml})$ (Abou-Zeid et al., 2016). Ginger extract and ginger nanoparticles were prepared in phosphate buffer saline (PBS) at 7.4 PH at concentration of 60 $\mu \mathrm{g} / \mathrm{ml}$ (Pashaei-Asl $\boldsymbol{e t}$ al., 2017). The concentration of freshly prepared isolated hepatocytes was $5 \times 10^{6}$ cell $/ \mathrm{ml}$, the cells were divided into 6 groups $(2 \mathrm{ml}$ of the suspended cells/tube).

The groups were treated as following, G1: served as control negative, G2: treated with GE only, G3 treated with GNPs only, G4: treated with APAP only, G5: treated with APAP + GE. G6: treated with APAP + GNPs. Ginger extract and ginger nanoparticles were preincubated with hepatocyte 30 minute prior to acetaminophen exposure in group 5 and 6 respectively.

\section{Assess the viability of cells}

Evaluation of cell viability was assessed by using trypan blue at two time points ( 0 and 120 minutes), by using the light microscope (Abdel-Aleem et al., 2014)

\section{Determination of enzymes leakage percent}

ALT and AST were assessed using reagent test kits purchased from SPECTRUM co. (Germany) according the method described by Alaa et al. (2016).

\section{Determination of oxidative stress in liver homogenate}

Lipid peroxidation (MDA) and catalase activity (CAT) were assayed by the method described by Weng et al. (2019).

\section{Cytopathological evaluation of isolated hepatocytes}

Ten $\mu 1$ of cell suspension from all groups at 120 min were placed on a glass slide and left to dry at room temperature. The cells were fixed by adding $10 \mu 1$ of absolute ethanol on the dried film and left to dry at room temperature. The slides were stained with hematoxylin and eosin according to (Kieman, 1999) and examined using BX43 light microscope and captured using Olympus BX 43 microscope linked to Olympus DP 27 CellSens dimensions software (Kieman, 1999).

\section{Statistical analysis}

One-way analyses of variance [ANOVA] was used to determine statistical significance followed by Tukey post-tests. Statistical analyses were performed using Software Graph Pad [*p $<0.05$, **p $<0.01$, ***p $<0.001]$

\section{RESULTS}

\section{Nanoparticles characterization}

The morphology of GNPs is shown in (Fig.1) GNPs demonstrated a spherical morphology. The average diameter of GNPs measured from SEM images were 102.3 to $998.3 \mathrm{~nm}$. This is in agreement with previous data of Zhuang $\boldsymbol{e t} \boldsymbol{a l}$. (2015).

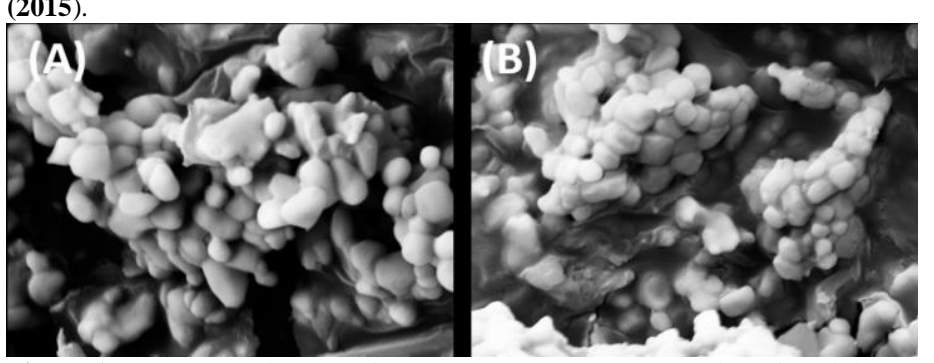

Figure $1(A \& B)$ SEM images of GNPs. Images are representative of a minimum of 3 independent samples, with $n>500$ NPs assessed in total (x1000).

\section{Cell viability}

Cell viability was assessed by using trypan blue. The results were obtained by counting viable and died cells of three fields under the light microscope at two time points ( 0 and 120 minutes) where died cells proved by presence of trypan blue inside their cytoplasm however viable cells were impermeable to trypan blue. A significant decrease in cell viability was observed after exposure to APAP compared to control cells. Neither GE nor GNPs exposure induced any significant change in the percentage of viability from the control. On the other hand, concurrent preincubation of the cells with GE or GNPs before exposure to APAP inhibited the decrease in the cell viability caused by APAP alone (Fig.2).

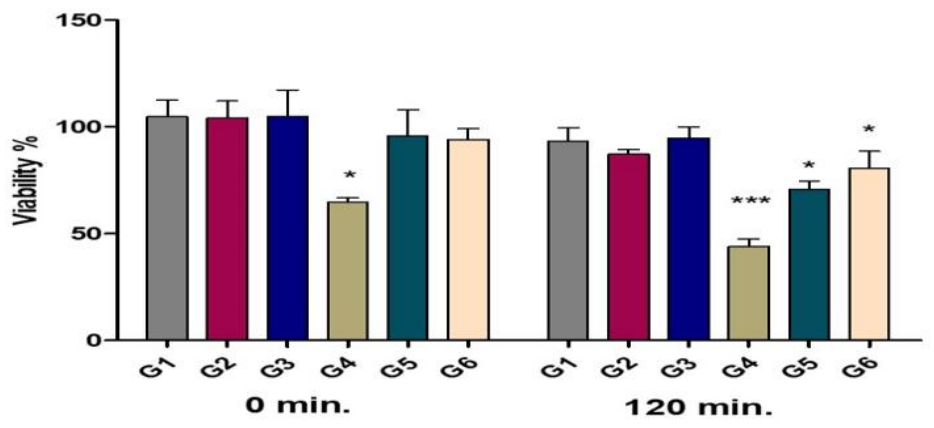

Figure 2 Showing the mean values of viability in all groups at different point times; $(* \mathrm{P}<0.05, * * \mathrm{P}<0.01, * * * \mathrm{P}<0.001)$.

\section{Determination of in vitro cytotoxicity}

Determination of cytotoxicity and damage of cell membrane was evaluated by measuring the level of both ALT and AST enzyme at different point times $(0,60$ and 120 min.). Exposure of hepatocytes to APAP resulted in a significan increase in the leakage of ALT and AST enzymes from hepatocytes compared with other groups especially at $120 \mathrm{~min}(\mathrm{P} \geq 0.001)$. Pretreatment of hepatocytes with GE or GNPs ameliorated the effects of APAP on enzyme leakage which become more notable at $120 \mathrm{~min}$., but it was more significant in group which 
preincubated with GNPs (Fig. 3\&4). On the other hand, neither GE nor GNPs caused any change in the enzyme's leakage at any time points.

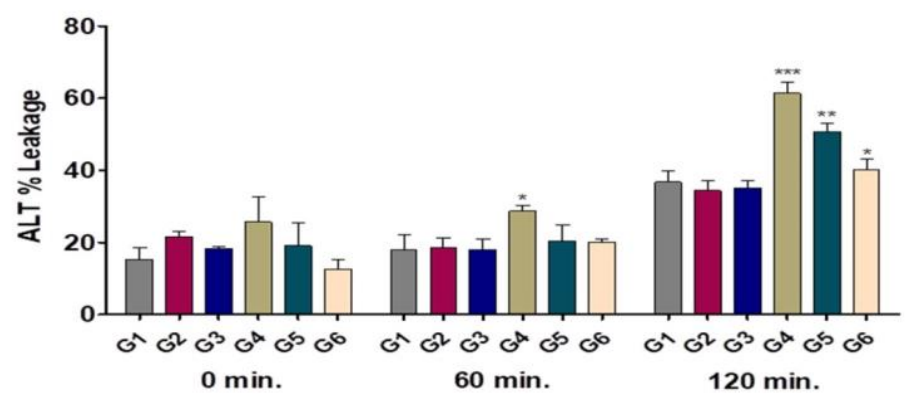

Figure 3 Showing the mean values of ALT in all groups at different point times; $(* \mathrm{P}<0.05, * * \mathrm{P}<0.01, * * * \mathrm{P}<0.001)$

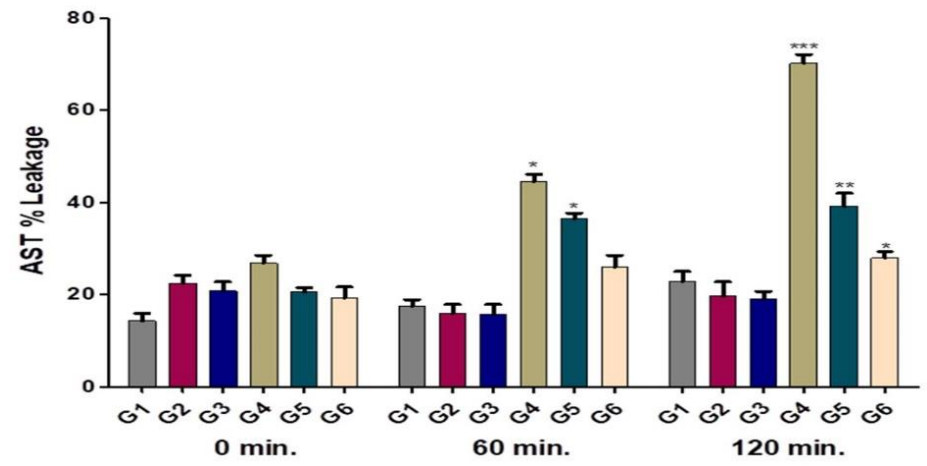

Figure 4 Showing the mean values of AST in all groups at different point times; $(* \mathrm{P}<0.05, * * \mathrm{P}<0.01, * * * \mathrm{P}<0.001)$

Assessment of oxidative stress-induced by acetaminophen in isolated hepatocytes was done by measuring cellular MDA and CAT levels. APAP caused significant increase in MDA content from isolated rat hepatocytes compared to control and other groups at 0,60 and $120 \mathrm{~min}$. ( $\mathrm{P} \geq 0.05, \mathrm{P} \geq 0.01$ and $\mathrm{P} \geq 0.001$, respectively). Neither GE nor GNPs alone showed any effect on MDA content at all time points. However, concomitant incubation of cells with GE and APAP or GNPs and APAP led to decrease the level of MDA relative to G4 (Fig. 5).

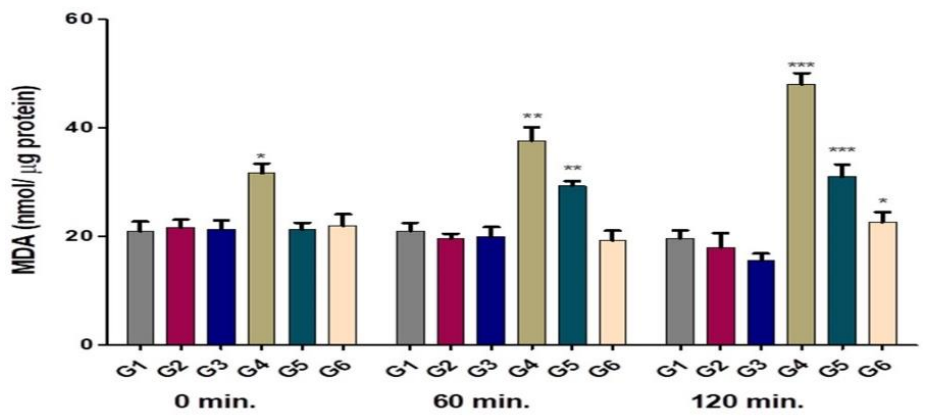

Figure 5 Showing the mean values of MDA in all groups at different point times; $(* \mathrm{P}<0.05, * * \mathrm{P}<0.01, * * * \mathrm{P}<0.001)$.

On other hand, exposure of hepatocyte to APAP induced drop in CAT level when compared with control hepatocyte at 60 and $120 \mathrm{~min}$. While preincubated cell with GE and GNPs prevent the depletion in CAT level which induced by APAP exposure. Moreover, there were no change in CAT levels in GE and GNPs treated cells in group 2 and 3 respectively (Fig. 6). The pre-incubation of GNPs with APAP treated hepatocytes achieved the best improvement of the hepatic oxidative status when compared with GE.

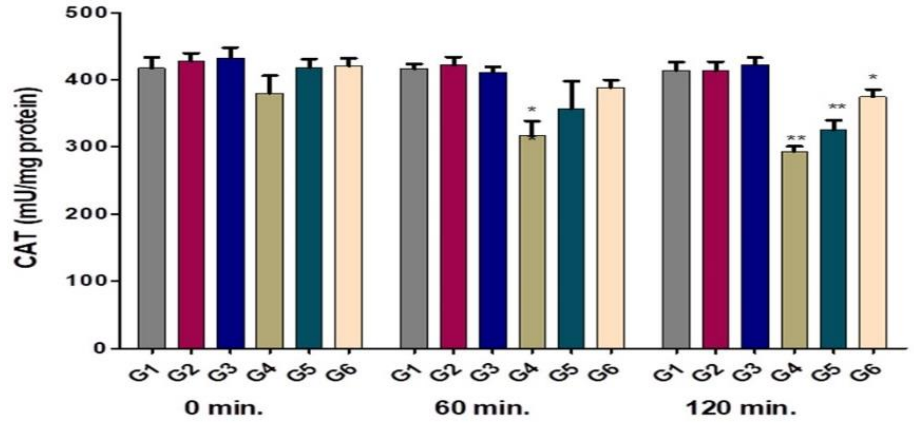

Figure 6. Showing the mean values of CAT in all groups at different point times; $(* \mathrm{P}<0.05, * * \mathrm{P}<0.01, * * * \mathrm{P}<0.001)$

\section{Cytopathological analysis}

On cytological level, control group (G1) showed normal hepatocytes which may be present as small groups (2-6 cells) or single cells. Normal hepatocytes are round or polygonal cells which have either one or two basophilic round/oval nuclei with fine dispersed chromatin, and granular cytoplasm which surrounded by intact cell membrane (Fig.7A\&B). The presence of debris and leukocytes in the background may be occurred. There were not any cytopathological changes in neither GE nor GNPs treated hepatocytes in (Fig.7C\&D)

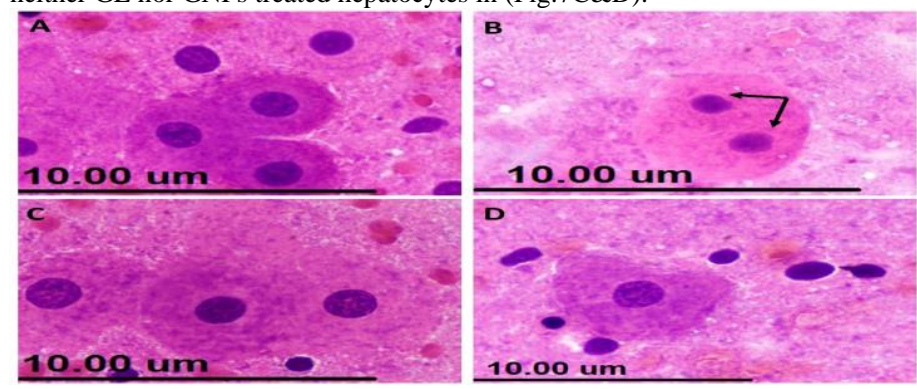

Figure 7 (A) Small group of hepatocytes from control group (G1) showing normal round cells with centric round nucleus and intact well-defined cell membrane. (B) Binucleated single hepatocyte from G1 showing eosinophilic granular cytoplasm. (C) Hepatocytes from ginger extract treated group (G2) showing normal structure. (D) Single hepatocyte from ginger nanoparticles treated group (G3) showing normal cytological structure. All slides stained with $\mathrm{H} \& \mathrm{E}$.

Acetaminophen treated hepatocytes (G4) showed cytopathological changes such as pyknosis, necrosis, foamy cytoplasm due to presence of multiple round clear vacuoles and cell lysis (Fig. 8).

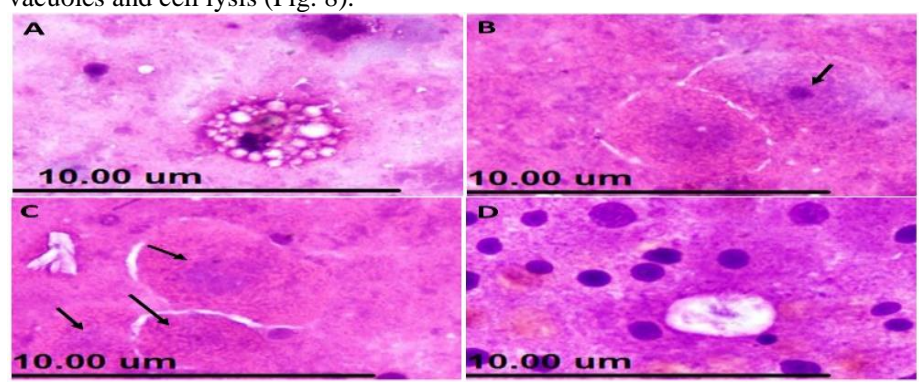

Figure 8 Hepatocytes of APAP treated group (G4) showing, (A) Hepatocellular cytoplasm appears foamy due to presence of multiple round clear vacuoles, nucleus appear pyknotic and move to peripheral side . (B) Two hepatocytes, one of them showing pyknotic nucleus (arrow) and the other one showing necrosis with complete lysis of nucleus-. (C) Three hepatocytes (arrows) showing necrosis and complete lysis of nucleus- (D) nucleus undergo lysis associated with complete ballooning of hepatocytes- All slides stained with H\&E.

While hepatocytes treated with GE and APAP in (G5) showed pyknosis (Fig.9A), vacuolar cytoplasm (Fig.9B), hydropic degeneration associated with lysis of nucleus (Fig. 9C), and necrosis (Fig 9D). On the other hand, minor cytological cytopathological changes were observed in GNPs+APAP treated hepatocytes. Most of hepatocytes appeared with normal cellular structure (Fig.9E), while the other cells showed minor vacuolation (Fig.9F). 


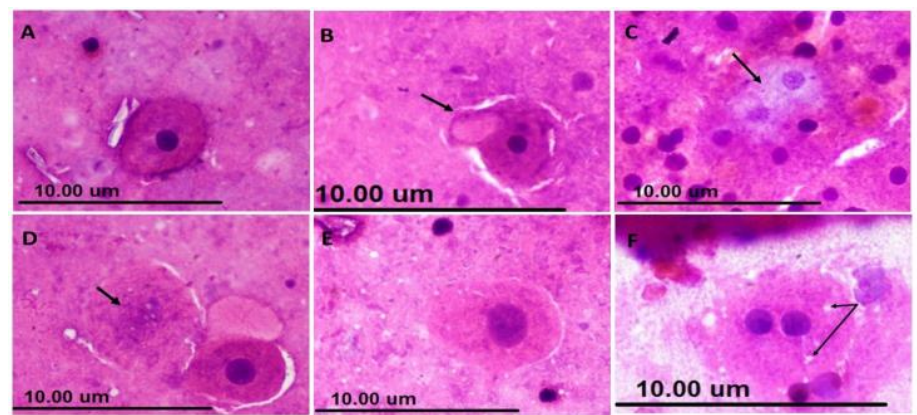

Figure 9 (A) Hepatocytes of GE+APAP treated group (G5) showing pyknotic nucleus with deep eosinophilic cytoplasm. (B) Single hepatocyte from G5 showing single vacuole with pyknotic nucleus and irregular cell membrane. (C) Hepatocytes from G5 showing vacuolar degeneration of cytoplasm (arrow), moreover the nucleus undergoes lysis- (D) Two hepatocytes from G5, one of them showing necrosis (arrow), and the other one showing single vacuole with pyknotic nucleus - (E) Single hepatocyte from GNPs+APAP treated group (G6) showing normal eosinophilic granular cytoplasm with central nucleus - (F) Single hepatocyte from GNPs+APAP treated group (G6) showing minor vacuoles in cytoplasm. All slides stained with H\&E.

\section{DISCUSSION}

Liver is an important organ which included in metabolism, detoxification and production of plasma proteins such as clotting proteins. Isolated hepatocytes provide a simple model to study liver disease and evaluated the hepatotoxicity, in addition to metabolism of xenobiotics (Guguen-guillouzo, 2002; Khater $\boldsymbol{e t}$ al., 2020). Another characteristic is that, isolated hepatocytes are stable under different conditions. So, isolated hepatocytes are the system of choice to study the hepatoprotective effect of some plant extracts. In general, chemically induced liver damage is more readily investigated in tissue culture than in whole animals (El-tawil \& Moussa, 2006).

This study aimed to evaluate the protective effect of ginger in both extract and nanosize form against cytotoxicity induced by acetaminophen on isolated hepatocytes. Since there are few studies evaluating the in vitro protective effects of ginger nanoparticles and ginger extract on primary isolated liver cells, acetaminophen was adjusted to $7 \mathrm{mM}(0.1 \mathrm{mg} / \mathrm{ml})$ to hepatocytes to induce marked cytotoxicity according to (Abou-Zeid $\boldsymbol{e t}$ al., 2016). Ginger extract and ginger nanoparticles were prepared at concentration of $60 \mu \mathrm{g} / \mathrm{ml}$ (Pashaei-Asl $\boldsymbol{e}$ al., 2017). Isolated hepatocytes were preincubated with GNPs and GE before exposure to APAP with $30 \mathrm{~min}$ to evaluate their hepatoprotective effects.

Our study showed a significant reduction in cell viability and increase in ALT \& AST leakage percent from the hepatocytes which exposure to APAP compared to control cells. These results are attributed to the ability of APAP to induce acute hepatocellular damage through a complicated consequences which include: (1) Transformation of cytochrome P450 into reactive compound which lead to reduction of glutathione ad bind with cellular protein; (2) production of ROS which cause damage of the cell membrane; (3) raised oxidative stress, combined with changes in calcium homeostasis causing change in mitochondrial permeability and loss its ability to produce ATP; (4) loss of ATP which leads to necrosis (Hinson et al., 2010; Imran et al., 2020).

Concurrent preincubation of the cells with GE and GNPs before exposure to APAP inhibited the decrease in the cell viability caused by APAP alone but it was more significant in hepatocytes incubated with GNPs. These results were attributed to the ability of ginger to preserve the structure of the cell membrane (Hasan et al., 2016). On the other hand, there was non-significant variation between GE and GNPs treated cells (G2\&G3) when compared with control cells (G1) in decreasing viability or increasing AST and ALT enzymatic leakage. Exposure of primary isolated rat hepatocytes to APAP significantly increased the MDA content and decreased the CAT levels. The hepatotoxic effect of acetaminophen is due to its conversion to $\mathrm{N}$-acetyl-p-benzoquinone-imine (NAPQI) which binds with glutathione. Once the depletion of glutathione store happened, the production of ROS and induction of oxidative stress occurred (Bunchorntavakul \& Reddy, 2013). Our study revealed that preincubation of the cells of (G5\&6) with both GE and GNPs lead to adjustment the levels of MDA and CAT. These results were attributed to phenolic active ingredient presents in ginger such as [6]-gingerol, [6]-shogaol which have a strong antioxidant activity in vitro because of their ability to be donors of hydrogen atoms and to scavenger of the free radicals (Syafitri et al., 2018). On other hand, ginger was reported to increase the gene expression of anti-oxidant enzymes such as GSH, SOD, and MDA (Jeena $\boldsymbol{e t}$ al., 2013), and decrease the expression of both superoxide production and catalase (Ahmed et al., 2008).

On the cytological level, APAP treated hepatocytes showed morphological and pathological changes such as pyknosis, fatty degeneration, and necrosis. Acetaminophen could induced cellular alteration by up-regulation of proinflammatory cytokines such as caspase-3, caspase-1, TNF- $\alpha$ and interleukin$1 \beta$ (Lin et al., 2014). Moreover, Kupffer cell reported to induce inflammatory mediator in addition to the role of infiltrated neutrophils in production of proteases and superoxide anion radicals which caused cell damage (Tachibana $\boldsymbol{e}$ al., 2011). but in our in vitro study we cannot suggest the interaction with the other cells. However, we can evaluate the primary effect of early APAP toxicity on the isolated hepatocyte depending on mitochondrial dysfunction theory (Abou-Zeid et al., 2016). Reactive metabolites of acetaminophen induce modification of mitochondrial proteins and increased the cytosolic calcium and peroxynitrite levels within the cells, which lead to formation of extra covalent bonds with cellular proteins producing mitochondrial dysfunction, increase the mitochondrial membrane which followed by releasing of the mitochondrial protein into the cytoplasm, resulting in cellular necrosis. Also, oxidative activity of acetaminophen could induce disturbance in microvilli which causing cell ballooning (Sakr \& Shalaby, 2012). Moreover, we could assess the possible mechanism of APAP toxicity under normal physiological media with estimation of the different pathological change and cellular interaction from our previous in vivo study (Bakr et al., 2019).

Ginger extract and ginger nanoparticles improved the histological architecture of hepatocytes by preservation the integrity of cellular membrane due to its antioxidant effect (Gholampour et al., 2017).

In our study, Ginger nanoparticles showed more hepatoprotective effect against acetaminophen than ginger extract. It may be attributed to the small size of nanoparticles which makes them proper for therapeutic effects. Several study reports that, nanoparticles less than $100 \mathrm{~nm}$ can enter cells, at less than $40 \mathrm{~nm}$ they can enter cell nucleus, and less than $35 \mathrm{~nm}$ they can pass the blood brain barrier (Murphy et al., 2016). Moreover, these particles have large surface area to volume ratio which making them more effective (Dutta \& Brahmachary, 2009). Moreover, the ingredients of ginger nanoparticles could be widely distributed in various organ including liver, and could be stable for long time under different conditions (Li et al., 2019). In addition to, they have ability to gather themselves within the cells and remain in colloidal state without coagulating for many hours (Dutta \& Brahmachary, 2009). On other hand, folate reported to play an important role in increasing the cellular uptake of nanoparticles through aiming the folate receptor (Mohammadi et al., 2016). The activity of folate on the surface of ginger nanoparticles was confirmed in vitro by using fluorescent and flow cytometry (Zhang et al., 2018)

Additionally, GNPs serve as stronger antioxidant against free radical compared to ginger extract. This result is attributed to shogaol which regulate the genetic expression of many antioxidant and detoxication enzymes (Abdu et al., 2017) Shogaols which carried by GNPs are in bind form in contrast the shogaols carried by GE which present in free form. So, less amount of shogaol carried by GNPs required for obtaining the equal effects on the hepatocytes compared with GE (Zhuang et al., 2015). Besides, shogaols in the GNPs have an critical role in the production of Nrf2 (Nuclear factor erythroid 2-related factor 2) which regulate adjust multiple cellular process such as, hepatocytes homeostasis, drugs metabolism and up regulate the expression of antioxidant enzymes (Zhuang $\boldsymbol{e} t$ al., 2015).

Furthermore, transformation of coarse substance into nano-size (nanosizing) lead to increase the surface area of the particles which result in facilitating the solubility of nanoparticles in water through rising the dissolution rate (Griffin $\boldsymbol{e} t$ al., 2018). As a result of increase solubility rate, the gradient concentration is raised. So, the uptake of nanoparticle by the cells through passive diffusion improved and become more efficient (Keck \& Muller, 2016). Besides, increase the surface area of nanoparticles has more benefits, such as providing more attached points on the surface so sticking to the surface turn out to be easier, stronger and extended (Griffin et al., 2018). Thus, improve the bioactivity of ginger nanoparticles insides the body when compared with coarse form (extract) due to the superior features. In addition to, ginger nanoparticles have been reported to cause no changes in blood parameters, body weight and histological structure of different organs (Zhang et al., 2016).

\section{CONCLUSION}

from our study we could conclude that, transforming the natural particles of ginger to nanoparticles (nanosizing) is supposed to give good therapeutic results by reducing the parameters of liver toxicity and providing a safe method for drug delivery especially to the liver (Xiao et al., 2014), counter to artificially synthesized nanoparticles which reported to deliver small doses of drugs to specific cells , but with limitation such as in vivo toxicity and limited production range (Zhang et al., 2017). Critically, GNPs exhibited excellent biocompatibility relative to ginger extract in vitro and in vivo according our pervious study (Bakr et al., 2019).

Acknowledgement: The authors would express their special thanks to ((all members of toxicology and pathology department, Cairo University)) for their support in completing our study.

\section{REFERENCES}

Abdel-Aleem, M. Y., Moawad, M. S., Mohamed, E. M. \& El-Tawil, O. S (2014). Cytotoxicity of silver nanoparticles (AgNPs) in freshly prepared isolated rat hepatocytes. Life Science Journal, 12, 82-90. 
Abdu, S. B., Abdu, F. \& Khalil, W. K. B. (2017). Ginger nanoparticles modulate the apoptotic activity in male rats exposed to dioxin-induced cancer initiation International Journal of Pharmacology, 13, 946-57. http://dx.doi.org/10.3923/ijp.2017.946.957

Abou-Zeid, S. M., El-Tawil, O. S. \& Gab-Allah, M. A. (2016). In vitro hepatoprotective effects of moringa oleifera extract against acetaminopheninduced hepatotoxicity. World Journal of Pharmacy and Pharmaceutical Sciences, 5, 50-70. http://dx.doi.org/10.20959/wjpps201612-8155

Adam, G. O., Rahman, M. M., Lee, S. J., Kim, G. B., Kang, H. S. \& Kim, S. J. (2016). Hepatoprotective effects of nigella sativa seed extract against acetaminophen-induced oxidative stress. Asian Pacific Journal of Tropical Medicine, 9, 221-27. http://dx.doi.org/10.1016/j.apjtm.2016.01.039

Ahmed, R. S., Suke, S. G., Seth, V. A., Chakraborti, K., Tripathi, A. \& Banerjee, B. D. (2008). Protective effects of dietary ginger (zingiber officinales rosc.) on lindane-induced oxidative stress in rats. Phyto Therapy Research, 22, 902-6.

Alaa, F. A., Sherein, S. A., Osama, S.E. \& Adel, M.B. (2016). Toxicological and Histopathological Studies on the Effect of Tartrazine in Male Albino Rats. International Journal of Biological, Biomolecular, Agricultural, Food and Biotechnological Engineering, $10(8)$, 469-474 http://scholar.waset.org/1999.1/10005306

Bakr AF, Abdelgayed SS, EL-Tawil OS and Bakeer AM, 2019. Assessment of ginger extract and ginger nanoparticles protective activity agains acetaminophen-induced hepatotoxicity and nephrotoxicity in rats. Pakistan Veterinary Journal, 39(4): 479-486. http://dx.doi.org/10.29261/pakvetj/2019.060 Bunchorntavakul, C. \& Reddy, K. R. (2013). Acetaminophen-related hepatotoxicity. Clinics in Liver Disease, 17, 587-607.

Dhanik, J., Arya, N. \& Nand, V. (2017). A review on zingiber officinale. Journal of Pharmacognosy and Phytochemistry, 6,174-84.

Dhayalan, M., Denison, M. I., Jegadeeshwari, J. K., Krishnan, L. A. \& Gandhi, N. N. (2017). In vitro antioxidant, antimicrobial, cytotoxic potential of gold and silver nanoparticles prepared using embelia ribes. Nat. Prod. Res, 31, 465-468. Dutta, R. \& Brahmachary, R. L. (2009). Natural nanoparticles: an overview, $2^{\text {nd }}$ edn, Dehram, LAP lambert academic publishing.

El-tawil, O. S. \& Moussa, S. Z. (2006). Antioxidant and hepatoprotective effects of thymoquinone against carbon tetrachloride-induced hepatotoxicity in isolated rat hepatocytes. Journal of the Egyptian Society of Toxicology, 34: 33-41.

Gabr, S. A., Alghadir, A. H. \& Ghoniem, G. A. (2019). Biological activities of ginger against cadmium-induced renal toxicity. Saudi journal of biological sciences, 26, 382-89. http://dx.doi.org/10.1016/j.sjbs.2017.08.008

Gholampour, F., Behzadi, F. G., Owji, S. M. \& Vatanparast, J. (2017). The protective effect of hydroalcoholic extract of ginger (zingiber officinale rosc.) against iron-induced functional and histological damages in rat liver and kidney. Avicenna Journal of Phytomedicine, 7, 542-53.

Griffin, S., Masood, M. I. N., Muhammad, J., Sarfraz, Ebokaiwe, M., Schäfer, A P. K., Keck, C. M. \& Jacob, C. (2018). natural nanoparticles: A particular matter inspired by nature. Antioxidants, 7, 1-21. http://dx.doi.org/10.3390/antiox7010003

Guguen-guillouzo, C. (2002). Culture of epithelial cells, $2^{\text {nd }}$ edn, Willey-liss, Inc, pp.337-339.

Hamed, M. A., Sanaa, A. A. \& El-rigal, N. S. (2012). Therapeutic potential of ginger against renal injury induced by carbon tetrachloride in rats. The Scientific World Journal. http://dx.doi.org/10.1100/2012/840421

Hasan, I.H., El-Desouky, M.A., Abd-Elaziz, G.M. \& Hozayen, W.G. (2016) protective effects of zingiber officinale against carbon tetrachloride induced liver fibrosis. International Journal of Pharmacy and Pharmaceutical Sciences, 8, 7781.

Hassan, S.M.A. \& Hassan, A.H. (2018). Assessment of toxicological effect of shogaol in albino mice. Pakistan Veterinary Journal, 38, 377-383. http://dx.doi.org/10.29261/pakvetj/2018.095

Hinson, J. A, Roberts, D. W. \& James, L. P. (2010). Mechanisms of acetaminophen-induced liver necrosis jack. Handb Exp Pharmacol, 196, 369405. http://dx.doi.org/10.1007/978-3-642-00663-0

Imran, M., Cao, S., Wan, S.F., Chen, Z., Saleemi, M.K., Wang, N., Naseem, M.N. \& Munawar, J. (2020). Mycotoxins - a global one health concern: A review. Agrobiological Records, 2, 1-16.

Jeena, K., Liju, V. B. \& Kuttan, R. (2013). Antioxidant, anti-inflammatory and antinociceptive activities of essential oil from ginger. Indian Journal of Physiology and Pharmacology, 57, 51-62.

Kandemir, F. M., Kucukler, S. E., Eldutar, C. Caglayan \& Gülçin, I. (2017) Chrysin protects rat kidney from paracetamol-induced oxidative stress, inflammation, apoptosis, and autophagy: A multi-biomarker approach. Scientia Pharmaceutical, 85: 4.

Keck, C.M. \& Muller, R. H. (2016). Drug nanocrystals of poorly soluble drugs produced by high pressure Homogenisation. European Journal of Pharmaceutics and Biopharmaceutics, 62, 3-16.

Khan, R. U., Naz, S., Nikousefat, Z., Tufarelli, V., Javdani, M., Qureshi, M. S. \& Laudadio, V. (2012). Potential applications of ginger (zingiber officinale) in poultry diets. World's Poultry Science Journal, 68, 45-52.

Khater, H.F., Ziam, H., Abbas, A., Abbas, R.Z., Raza, M.A., Hussain, K. Younis, E.Z., Radwan, I.T. \& Selim, A. (2020). Avian coccidiosis: Recent advances in alternative control strategies and vaccine development Agrobiological Records 1, 11-25.

Kieman, J. A. (1999). Histological and histochemical methods. theory and practice, $3^{\text {rd }}$ edn, Butterworth Heinemann, Oxford, Boston, New Dehli.

Li, L., Cui, Y., Guo, X., Ma, K., Tian, P. \& Feng, J. (2019). pharmacokinetics and tissue distribution of gingerols and shogaols from ginger (zingiber officinale rosc.) in rats by UPLC-Q-Exactive-HRMS. Molecules, 24, 1-12.

Lin, Z., Wu, F. \& Lin, S. (2014). adiponectin protects against acetaminopheninduced mitochondrial dysfunction and acute liver injury by promoting autophagy in mice. Journal Hepatology, 61,825-831.

Mahmoud, M. Y., Steinbach-rankins J. M. \& Demuth, D. R. (2019). functional assessment of peptide-modified PLGA nanoparticles against oral biofilms in a murine model of periodontitis. Journal of Controlled Release, 297, 3-13.

Mekuriya, W. \& Mekibib, B. (2018). Review on the medicinal values of ginger for human and animal ailments. Journal of Veterinary Science \& Technology, 9 , 9-12.

Mohammadi, M., Li, Y. \& Abebe, D. G. (2016). Folate receptor targeted threelayered micelles and hydrogels for gene delivery to activated macrophages. Journal Control Release, 244, 69-79.

Murphy, F., McAlea, Mullins, E. M. \& M. (2016). Managing risk in nanotechnology. Topics in governance, assurance and transfer, $1^{\text {st }}$ edn, Springer International Publishing, Switzerland, pp.29-49.

Pashaei-Asl, R., Pashaei-Asl, F., Gharabaghi, M., Khodadadi, K., Ebrahimi, M., Ebrahimi, E. \& Pashaiasl, M. (2017). The inhibitory effect of ginger extract on ovarian cancer cell line; Application of Systems Biology. Advanced Pharmaceutical Bulletin, 7, 241-249.

Ramachandran, A. \& Jaeschke, H. (2017). Mechanisms of acetaminophen hepatotoxicity and their translation to the human pathophysiology. Journal of Clinical and Translational Research, 3, 157-169. http://dx.doi.org/10.1126/science.1249098

Rashid, U., Khan, M. R. \& Sajid, M. (2016). Hepatoprotective potential of fagonia olivieri dc. against acetaminophen induced toxicity in rat. $B M C$ Complementary and Alternative Medicine, 16,1-18.

Sakr, S. A., Mahran, H. A. \& Lamfon, H. A. (2011). Protective effect of ginger (zingiber officinale) on adriamycin -induced hepatotoxicity in albino rats. Journal of Medicinal Plants Research, 5, 33-40.

Sakr, S. A. \& Shalaby, S. Y. (2012). Metiram-induced histological and histochemical alterations in liver and kidney of pregnant mice. Life Science Journal, 9,71-76

Shakya, S. R. (2015). Medicinal uses of ginger (zingiber officinale roscoe) improves growth and enhances immunity in aquaculture. International Journal of Chemical Studies, 3,83-87.

Shams Al-dain, Z. Q. \& Jarjeis, E. A. (2015). Vital impact of using ginger roots powder as feed additive to the rations of local friesian dairy cows and its effect on production \& economic efficiency of milk and physiological of blood. Kufa Journal for Veterinary Sciences, 6: 155-165.

Sirichote, P. C. \& Anchalee, D. (2008). Chemical and bioactive properties of ginger extract from SC-CO 2extraction. Asian Journal of Food and Agroindustry, 1, 29-36.

Stan, M., Lung, I., Soran, M., Leostean, C., Popa, A., Stefan, M., Lazar, M. D. Oprais, O., Silipas, T. \& Parva, A. S. (2017). Removal of antibiotics from aqueous solutions by green synthesized magnetite nanoparticles with selected agro-waste extracts. Process Safety and Enviromental Protection, 107,357-372.

Sutardi, L. N., Wientarsih, I., Handharyani, E., Andriani, M. \& Setiyono, A (2015). Indonesian wild ginger (zingiber $s p$ ) extract: antibacterial activity against mycoplasma gallisepticum. IOSR Journal of Pharmacy, 5,59-64.

Syafitri, D. M., Levita, J., Mutakin, M. \& Diantini, A. (2018). A Review: Is ginger (zingiber officinale var. roscoe) potential for future phytomedicine?. JAS, 8, http://dx.doi.org/10.24198/ijas.v8i1.16466

Tachibana, S., Shimomura, A. \& Inadera, H. (2011). Toxicity monitoring with primary cultured hepatocytes underestimates the acetaminophen-induced inflammatory responses of the mouse liver. The Tohoku Journal of Experimental Medicine, 225, 263-72.

Wang, J., Ke, W., Bao, R., Hu, X. \& Chen, F. (2017). Beneficial effects of ginger zingiber officinale roscoe on obesity and metabolic syndrome: A review. Annals of the New York Academy of Science, 1398,183-198.

Weng, Q., Li, B., Liu, Z., Liu. K., Wu, W. \& Liu, H. (2019). ACTH induces oxidative stress and decreases DNA methylation of Fkbp5 in Suhuai sow. Pakistan Veterinary Journal, 39, 401-405. http://dx.doi.org/10.29261/pakvetj/2019.083

Woolbright, B. L. \& Jaeschke, H. (2017). Role of the Inflammasome in Acetaminophen-Induced Liver Injury and Acute Liver Failure Benjamin. Journal of Hepatology, 66, 836-48. http://dx.doi.org/10.1016/j.jhep.2016.11.017

Xiao, B., Laroui, H., Viennois, E., Ayyadurai, S., Charania, M. A., Zhang, Y., Zhang, Z., Bakeer, M. T., Zhang, B., Gewirtz, A. T. \& Merlin, D. (2014) Nanoparticles with surface antibody against CD98 and carrying CD98 small interfering RNA reduce colitis in mice. Gastroenterology, 146,1289-1300.

Yang, M., Liu, C., Jiang, J., Zuo, G., Lin, X., Yamahara, J., Wang, J. \& Li, Y (2014). Ginger extract diminishes chronic fructose consumption-induced kidney injury through suppression of renal overexpression of proinflammatory cytokines in rats. BMC Complementary and Alternative Medicine, 14,1-12. 
Zhang, M., Xiao, B., Wang, H., Han, M. K., Zhang, Z., Viennois, E., Xu, C. \& Merlin, D. (2016). Edible ginger-derived nano-lipids loaded with doxorubicin as a novel drug-delivery approach for colon cancer therapy. Molecular Therapy, 24,1783-1796. http://dx.doi.org/10.1080/21688370.2015.1134415

Zhang, M., Viennois, E., Prasad, M., Zhang, Y., Wang, L., Zhang, Z., Han, M.K (2017). Edible ginger-derived nanoparticles: a novel therapeutic approach for the prevention and treatment of inflammatory bowel disease and colitis-associated cancer. Biomaterial, 101,321-340.

Zhang, M., Xu, C., Liu, D., Han, M. K., Wang, L. \& Merlina, D. (2018). Ora delivery of nanoparticles loaded with ginger active compound, 6-shogaol, attenuates ulcerative colitis and promotes wound healing in a murine model of ulcerative colitis. Journal of Crohn's and Colitis, 12,217-229.

Zhang, M., Viennois, E., Xu, C. \& Merlin, D. (2017). Plant derived edible nanoparticles as a new therapeutic approach against diseases. Tissue Barriers, 4 $1-9$.

Zhuang, X., Deng, Z., Mu, J., Zhang, L., Yan, J., Miller, D., Feng, W., Mcclain, C.J. \& Zhang, H. (2015). Ginger-derived nanoparticles protect against alcoholinduced liver damage. Journal of Extracellular Vesicles, 4,28713. http://dx.doi.org/10.3402/jev.v4.28713 